\title{
The eustachian tube: a new renaissance
}

The renewed interest in the eustachian tube has enriched the practice of otolaryngology and is contributing to our patients' wellbeing.

It took over a hundred years for Bartolomeus Eustachius' (circa 1510-1574) work on the tube to be recognised. The work by Valsalva, Toynbee and Politzer in the subsequent three centuries contributed in large measures to our current understanding, and yet the eustachian tube remains an enigma.

Eustachian tube dysfunction is an all-encompassing condition that results mostly from pressure regulation impairment, with annoying symptoms of muffled hearing, earache and popping sensation. It remains a diagnostic and operational challenge.

In the current issue of The Journal of Laryngology \& Otology, MacKeith and Bottrill ${ }^{1}$ report their experience on the effectiveness of polymethylsiloxane elastomer augmentation surgery in the management of a patulous eustachian tube, a condition that causes autophony to voice and respiration. Previous papers include the first published description of using a computed tomography guided, transcutaneous approach to augmentation by silicone elastomer ${ }^{2}$ and the patching of the tympanic membrane to alleviate symptoms of a patulous eustachian tube. ${ }^{3}$ That a patulous eustachian tube could result from percutaneous balloon microcompression for trigeminal neuralgia ${ }^{4}$ and after surgery for weight loss ${ }^{5}$ adds to the problem.

Poe $^{6}$ reported on the measurements of eustachian tube dilation by video endoscopy and Augustine et al. ${ }^{7}$ showed that dynamic slow-motion video endoscopy overestimates eustachian tube function. Tarabichi and Kapadia $^{8}$ described a possible algorithm for the evaluation of eustachian tube obstructive disorders in chronic ear disease, and Mills and Hathorn ${ }^{9}$ considered the role of the eustachian tube in adult otitis media with effusion.

Hwang and colleagues ${ }^{10}$ systematic review on balloon dilation for eustachian tube dysfunction, which included over 700 hundred eustachian tube dilations in 474 patients, showed that balloon dilation is safe. Jufas and Patil ${ }^{11}$ raised the issue of a narrow evidence base for this procedure in their systematic review. There is potential for improvement in patients' symptoms, but long-term results remain elusive. There is a need for care in the promotion of sales of devices by manufacturers so that this is consistent with the current level of evidence.

\section{MUSHEER HUSSAIN EDWARD FISHER ROBIN YOUNGS JONATHAN FISHMAN Senior Editors}

\section{References}

1 MacKeith SA, Bottrill ID. Polydimethylsiloxane elastomer injection in the management of the patulous eustachian tube. $J$ Laryngol Otol 2016;130:805-10

2 Rodrigues JC, Waddell A, Cook JL. A novel, computed tomography guided, trans-cutaneous approach to treat refractory autophony in a patient with a patulous eustachian tube. J Laryngol Otol 2014;128:182-4

3 Boedts M. Paper patching of the tympanic membrane as a symptomatic treatment for patulous eustachian tube syndrome. J Laryngol Otol 2014;128:228-35

4 Cresswell M, Buckland J, West P, Sparrow O. Patulous eustachian tube after percutaneous balloon microcompression for trigeminal neuralgia: case report. J Laryngol Otol 2014;128: 478-80

5 Alhammadi M, Jönsson R, Olbers T, Yassin O. Patulous eustachian tube complicating gastric bypass surgery. J Laryngol Otol 2009;123: $1058-60$

6 Poe D. Measurements of eustachian tube dilation by video endoscopy. Otol Neurotol 2011;32:794-8

7 Augustine AM, Varghese L, Michael RC, Albert RR, Job A. The efficacy of dynamic slow motion video endoscopy as a test of eustachian tube function. J Laryngol Otol 2013;127: $650-5$

8 Tarabichi M, Kapadia M. Preoperative and intraoperative evaluation of the eustachian tube in chronic ear surgery. Otolaryngol Clin North Am 2016:S0030-6665(16)30048-2. Epub 2016 Jul 25

9 Mills R, Hathorn I. Aetiology and pathology of otitis media with effusion in adult life. J Laryngol Otol 2016;130:418-24

10 Hwang SY, Kok S, Walton J. Balloon dilation for eustachian tube dysfunction: systematic review. J Laryngol Otol 2016; 130(suppl 4):S2-6

11 Jufas N, Patel N. Transtympanic balloon dilatation of the eustachian tube: systematic review. J Laryngol Otol 2016;130: 425-30 